\title{
Mechanistic Studies of Proton-Coupled Electron Transfer in a Calorimetry Cell
}

Fangfang Zhong and Ekaterina V. Pletneva*

Department of Chemistry, Dartmouth College, Hanover, NH 03755

*Corresponding author: ekaterina.pletneva@dartmouth.edu, Tel. 1-603-646-0933, Fax:

$1-603-646-3946$

Supporting Information 


\section{Materials and Methods}

Site-Directed Mutagenesis, Protein Expression, and Purification. Point mutations in the Rbs $\left(\mathrm{WT}^{*}\right)^{1}$ plasmid were introduced with a QuikChange kit. The WT* and mutant proteins were expressed and purified as previously described. ${ }^{2,3}$ All of the variants used in this work had the background mutations $\mathrm{K} 72 \mathrm{~A} / \mathrm{C} 102 \mathrm{~S}$ to prevent coordination of Lys72 to the heme iron and formation of Cys 102-linked dimers.

Metal Complexes. Potassium ferricyanide $\mathrm{K}_{3} \mathrm{Fe}(\mathrm{CN})_{6}$ and ruthenium(III) hexaammine chloride $\mathrm{Ru}\left(\mathrm{NH}_{3}\right)_{6} \mathrm{Cl}_{3}$ were obtained from Acros Organics and Strem Chemicals, respectively. $\mathrm{Co}$ (phen) ${ }_{3} \mathrm{Cl}_{3}$ was synthesized using a published procedure. ${ }^{4}$ Concentrations of complex metal ions in prepared solutions were determined spectrophotometrically, using known extinction coefficients. $^{5-7}$

Spectroscopic and Spectroelectrochemistry Measurements. Electronic absorption spectra and circular dichroism (CD) spectra were acquired on an Agilent 8453 diode-array spectrophotometer and a JASCO-J815 CD spectropolarimeter, respectively. Spectroelectrochemistry measurements were performed as previously described. ${ }^{8}$

Isothermal Titration Calorimetry (ITC). All experiments were performed at $25^{\circ} \mathrm{C}$ using either MicroCal PEAQ-ITC or VP-ITC instruments placed in a glove box under a nitrogen atmosphere. All the buffers were at $10 \mathrm{mM}$ with $100 \mathrm{mM}$ added sodium chloride. The following buffers were used: $\mathrm{pH} 5.50$ (sodium maleate, MES and piperazine), $\mathrm{pH}$ 5.80, 6.00, and 6.50 (sodium maleate, MES and Bis-Tris), pH 6.25 (sodium maleate, MES, Bis-Tris, PIPES, and ACES), pH 6.75, 7.00 and 7.20 (sodium maleate, Bis-Tris and MOPS), pH 8.00 (HEPES, Tricine and Tris), $\mathrm{pH} 8.50$ (Borate, Tricine and Tris), $\mathrm{pH} 9.00$ (Borate, CHES and Tris) and $\mathrm{pH} 9.50$ (Borate, CHES and piperazine). Ferrous cyt $c$ proteins were prepared by adding sodium dithionite to a protein solution in a nitrogen-filled glove box (COY Laboratory Products) and the excess of reducing agent was then removed by running through a PD-10 column. The reaction cell contained $20-100 \mu \mathrm{M}$ ferrous cyt $c$ and the injection syringe was filled with $0.2-1.0 \mathrm{mM}$ 


\section{$\mathrm{Co}(\text { phen })_{3} \mathrm{Cl}_{3}$.}

While the $\mathrm{Co}(\text { phen })_{3}{ }^{3+}$ ITC experiments allowed for accurate determination of reaction enthalpies $\Delta H_{\mathrm{obs}}$ for all the three variants, the titration curve of the low-potential T78C/K79G cyt $c$ lacked the definition in the transition region (Figure S7A), necessary for calculations of reduction potentials, and therefore we have employed instead $\mathrm{Ru}\left(\mathrm{NH}_{3}\right)_{6}{ }^{3+}$ as an oxidant in this subset of experiments (Figure S7B).

Relevant equilibria for all the reactions in the calorimetry cell are listed in Schemes S1 and $\mathrm{S} 2$. Scheme S1 depicts the relationship between the protonation and ligand-switch (conformational exchange) equilibria in ferric $\mathrm{K} 79 \mathrm{H}$ and $\mathrm{T} 78 \mathrm{C} / \mathrm{K} 79 \mathrm{G}$ cyt $c$. No ligand switch takes place in ferrous forms of these variants.

\section{Scheme S1. Protonation and Ligand-Switch Equilibria in K79H and T78CK79G}

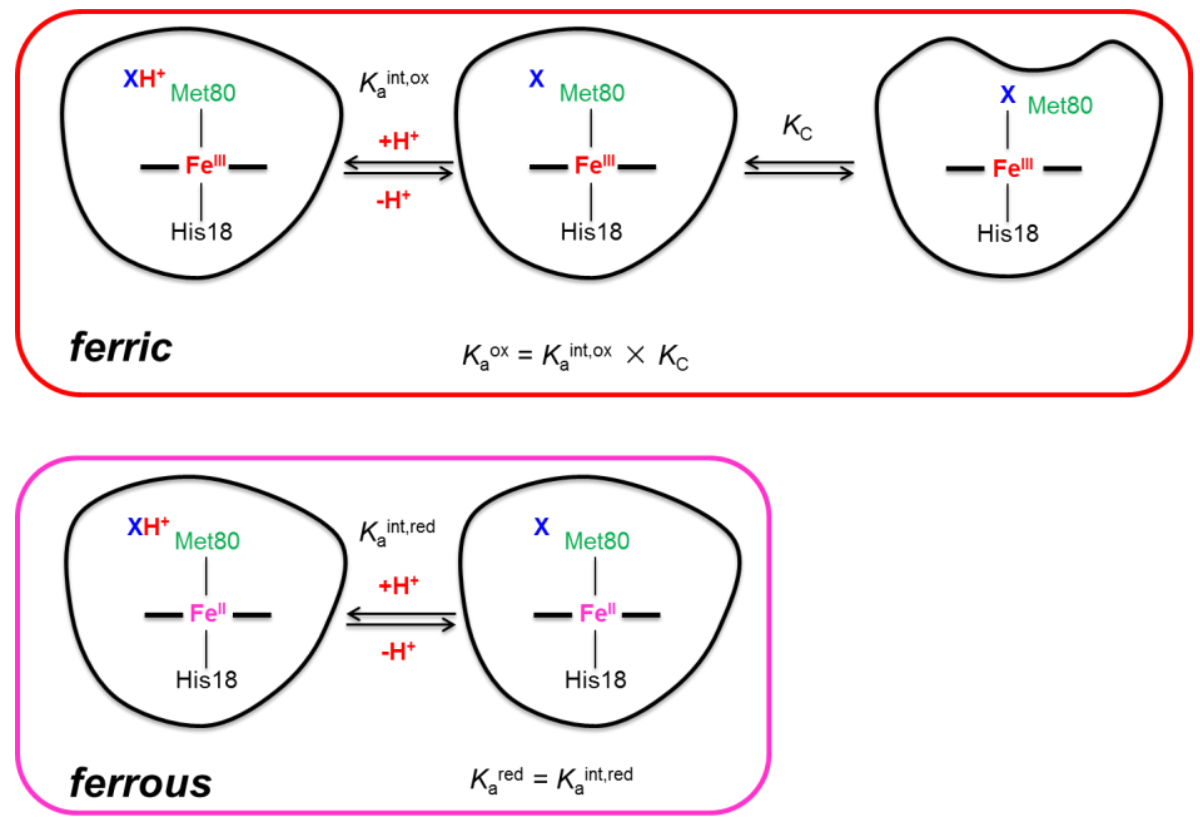




\section{Scheme S2. Equilibria for Reactions in a Calorimetry Cell in This Study}

$$
\begin{aligned}
& \text { His18-Fe"l-Met80 } \stackrel{K^{M-M}}{\rightleftarrows} \text { His18-Fe"ll-Met80 + } e^{-} \\
& \text {His18-Fe"l-Met80 } \stackrel{K^{M-x}}{\rightleftarrows} \text { His18-Fe }{ }^{I I I}-\mathbf{X}+e^{-} \\
& \mathrm{Co}(\text { phen })_{3}{ }^{3+}+e^{-} \stackrel{K\left(\mathrm{Co}^{3+2+}\right)}{\rightleftarrows} \mathrm{Co}(\text { phen })_{3}{ }^{2+} \\
& \mathrm{Ru}\left(\mathrm{NH}_{3}\right)_{6}{ }^{3+}+\mathrm{e}^{-} \stackrel{\mathrm{K}\left(\mathrm{Ru}^{3+12+} \rightleftarrows\right.}{\rightleftarrows} \mathrm{Ru}\left(\mathrm{NH}_{3}\right)_{6}{ }^{2+} \\
& \text { His18-Fe'll-Met80 XH+ } \stackrel{K_{\mathrm{a}}^{\text {int,ox }}}{\rightleftarrows} H i s 18-F e^{\text {IIII-Met80 }} \text { X }+\mathrm{H}^{+} \\
& \uparrow K_{c} \\
& \text { His18-Fe }{ }^{I I I}-\mathbf{X} \\
& \text { His18-Fell-Met80 } \mathrm{XH}^{+} \stackrel{K_{\mathrm{a}}^{\text {int,red }}}{\rightleftarrows} \text { His18-Fell-Met80 } \mathrm{x}+\mathrm{H}^{+}
\end{aligned}
$$

ITC data were analyzed using the MicroCal PEAQ-ITC or VP-ITC analysis software yielding dissociation constants $K_{\mathrm{D}}$, binding stoichiometry $N$ and changes in enthalpy $\Delta H_{\text {obs. }}$ The equilibrium constant for the reaction $K_{\text {eq }}$ was calculated using eq $\mathrm{S}^{9,10}$ and the potential difference $\Delta E_{\mathrm{m}}$ was calculated using eq $\mathrm{S} 2 .{ }^{10}$ The reduction potentials of oxidants $\mathrm{Co}(\mathrm{phen})_{3}{ }^{3+}$ $E\left(\mathrm{Co}^{3+/ 2+}\right)$ and $\mathrm{Ru}\left(\mathrm{NH}_{3}\right)_{6}{ }^{3+} E\left(\mathrm{Ru}^{3+/ 2+}\right)$ were taken as $377 \pm 2 \mathrm{mV}^{11}$ and $51 \mathrm{mV}^{12}$, respectively, and the reduction potential of the heme iron in cyt $c E\left(\mathrm{Fe}^{3+/ 2+}\right)$ was calculated using eq S3.

$$
\begin{gathered}
K_{\mathrm{eq}}=N \times[\text { oxidant }] / K_{\mathrm{D}} \\
n F \Delta E_{\mathrm{m}}=R T \ln K_{\mathrm{eq}} \\
\Delta E_{\mathrm{m}}=E\left(\mathrm{Co}^{3+/ 2+} \text { or } \mathrm{Ru}^{3+/ 2+}\right)-E\left(\mathrm{Fe}^{3+/ 2+}\right)
\end{gathered}
$$

Determination of parameters $\Delta H_{0}, \Delta n_{\mathrm{H}+}, \mathrm{p} K_{\mathrm{a}}^{\text {ox }}, \mathrm{p} K_{\mathrm{a}}^{\text {red }}, \Delta H^{\mathrm{M}-\mathrm{M}}, \Delta H^{\mathrm{M}-\mathrm{X}}$, and $\Delta H_{\text {prot }}$ are described in the main text. 
Molecular Dynamics Simulations. Models of K79H and T78C/K79G were constructed based on the crystal structures of yeast iso-1 cyt $c$ (2YCC.pdb ${ }^{13}$ and 1YCC.pdb ${ }^{14}$ for ferric and ferrous forms, respectively). NAMD (Not Just a Molecular Dynamics) program was used for simulations with CHARMM force field, and structural analysis was performed by VMD (Visual Molecular Dynamics) program. Heme iron ligands were linked to the heme iron before the energy minimization. Solvent accessible surface area was calculated by POPS (Parameter OPtimized Surfaces) ${ }^{15}$ method.

Kinetics of Oxidation of $\mathbf{K 7 9 H}$ and T78C/K79G. A BioLogic SFM-300 stopped-flow instrument was employed to follow changes in the Soret, Q-band, and charge-transfer spectral regions. Kinetic traces were analyzed using SFit (BioLogic) or MATLAB 2015b.

Ferrous proteins and stock solutions of $\mathrm{Co}(\mathrm{phen})_{3} \mathrm{Cl}_{3}$ or $\mathrm{K}_{3} \mathrm{Fe}(\mathrm{CN})_{6}$ were prepared in a deoxygenated $10 \mathrm{mM}$ buffer containing $100 \mathrm{mM} \mathrm{NaCl}$ in a nitrogen-filled glove box (COY Laboratory Products). The buffers used in the kinetics experiments were sodium acetate (pH 4.5-5.5), sodium maleate $(\mathrm{pH}$ 6.0-7.0), sodium phosphate $(\mathrm{pH} 7.5-8.0)$ and sodium borate $(\mathrm{pH}$ 8.5 to 9.5). Oxidation of $\mathrm{K} 79 \mathrm{H}$ and $\mathrm{T} 78 \mathrm{C} / \mathrm{K} 79 \mathrm{G}$ cyt $c$ by $\mathrm{Fe}(\mathrm{CN})_{6}{ }^{3-}$ was fast and, at $\left[\mathrm{K}_{3} \mathrm{Fe}(\mathrm{CN})_{6}\right]=1.5 \mathrm{mM}$, this step (with a rate constant $k_{1}$ in Scheme 1) was finished within the dead time of the instrument $(7.5 \mathrm{~ms})$. These conditions were well suited for observation of a weak charge-transfer band at $\sim 695 \mathrm{~nm}$ owing to the transient population of the Met-ligated ferric species in the ligand-switch step. The final concentration of cyt $c$ was between 50 and $80 \mu \mathrm{M}$ and the concentration of $\mathrm{Fe}(\mathrm{CN})_{6}{ }^{3-}$ varied from 0.3 to $1.5 \mathrm{mM}$. The ligand-switch kinetics were monoexponential for K79H ( $k_{2}$ in Scheme 1, Figure S3). For T78C/K79G, these kinetics were also monoexponential at $\mathrm{pH}<7.0$ but became biexponential at higher $\mathrm{pH}$ (Figure S3). The minor $\left(<10 \%\right.$ amplitude) phase for this variant had the rate constant $k_{3}=6.6 \pm 0.2 \mathrm{~s}^{-1}$, independent of $\mathrm{Fe}(\mathrm{CN})_{6}{ }^{3-}$ concentration or $\mathrm{pH}$. This phase likely corresponds to a switch from Met80 to Lys73 at the ferric heme iron in the minor species having oxidized Cys78. We have previously shown that Lys73 is able to coordinate to the ferric heme iron in T78C/K79G. ${ }^{2}$ The magnitude of the rate 
constant $k_{\mathrm{f}}=8.4 \pm 1.9 \mathrm{~s}^{-1}$ for the Met-to-Lys ligand exchange in $\mathrm{K} 79 \mathrm{G}^{16}$ is in accord with this assignment.

Oxidation kinetics of $\mathrm{T} 78 \mathrm{C} / \mathrm{K} 79 \mathrm{G}$ by $\mathrm{Co}($ phen $) 3^{3+}$ were sufficiently slow to allow for observation of both ET and ligand-switch steps. In these experiments, the final concentration of the protein was $5-10 \mu \mathrm{M}$ and the concentration of $\mathrm{Co}(\text { phen })_{3}{ }^{3+}$ varied from 0.2 to $1 \mathrm{mM}$. The spectral changes in the Soret and Q-band regions were biexponential at $\mathrm{pH}<7.0$ and triexponential at higher $\mathrm{pH}$ (Figure S2). The ligand-switch rate constants $k_{2}$ from these experiments were the same as observed in the experiments with $\mathrm{K}_{3} \mathrm{Fe}(\mathrm{CN})_{6}$ that followed changes in the charge-transfer band. Figure S2D displays the $\mathrm{pH}$ dependence of the rate constant $k_{2}$ for Met80-to-Cys78 ligand switch.

Thermal Denaturation of Ferrous WT* and K79H. Ferrous samples of WT* and K79G were prepared by treatment of the protein solutions at $\mathrm{pH} 7.4$ with sodium dithionite in a glove box and then exchanging buffers to that with a desired $\mathrm{pH}$ by a PD-10 desalting column. Melting curves were recorded by monitoring CD signals at $222 \mathrm{~nm}$ of 5-8 $\mu \mathrm{M}$ proteins in a $4 \mathrm{~mm}$ sealed quartz cuvette. An excess of dithionite $(\sim 500 \mu \mathrm{M})$ was added into each ferrous sample to ensure reducing conditions throughout the scan. The temperature range of each scan was $20-90{ }^{\circ} \mathrm{C}$. The buffers were at $10 \mathrm{mM}$ and contained added $100 \mathrm{mM} \mathrm{NaCl}$. Samples were transferred to cuvettes and then sealed in the glove box, and the oxidation state of the protein was confirmed before and after each melting experiment using absorption spectra. Thermodynamic parameters were extracted through nonlinear curve fitting of the CD signals as previously described. ${ }^{8}$ 
Table S1. Enthalpies of Protonation $\Delta H_{\text {prot }}$ of Common Basic Groups in Proteins

\begin{tabular}{lcc}
\hline Group & Amino Acid(s) & $\Delta H_{\text {prot }}(\mathrm{kcal} / \mathrm{mol})$ \\
\hline Imidazole & His & $-7.1^{17}$ \\
Thiolate & Cys & $-8.6^{17}$ \\
Carboxylate & Asp, Glu & $2.1^{18}$ \\
Guanidine & Arg & $-18.2^{19}$ \\
\hline
\end{tabular}

Table S2. Potentials and Enthalpies of Heme Iron Reduction (His18-Fe ${ }^{\mathrm{III}}-\mathrm{X}+e^{-} \rightarrow$ His18-Fe ${ }^{\mathrm{II}}$-Met80) for Yeast iso-1 Cyt $c$ Variants from Electrochemistry Studies

\begin{tabular}{cccc} 
Variant & $\mathrm{X}$ & $E(\mathrm{mV})$ & $\Delta H(\mathrm{kcal} / \mathrm{mol})$ \\
\hline WT $^{*}$ & Met80 & $287 \pm 2^{16}$ & $-14.6 \pm 0.2^{20, a}$ \\
K79H & His79 & $266 \pm 2^{b}\left(229 \pm 3^{20, c}\right)$ & $-15.8 \pm 0.2^{20, c}$ \\
T78C/K79G & Cys78 & $82 \pm 3^{2, b}$ & n. a. \\
\hline
\end{tabular}

${ }^{a}$ WT yeast iso-1 cyt $c$ having Tml72 and C102S. ${ }^{b}$ From spectroelectrochemistry experiments run in the oxidative direction as in the ITC experiments in this study. ${ }^{c} \mathrm{~F} 82 \mathrm{H}$ yeast $i s o-1$ cyt $c$, another His-to-Met switchable variant.

Table S3. Solvent Exposure (\%) of His79 and Cys78 Residues in Structural Models of Switchable Cyt $c$ Variants in This Study ${ }^{a, b}$

\begin{tabular}{lcccc}
\hline \multirow{2}{*}{ Variant } & \multirow{2}{*}{ X } & \multicolumn{3}{c}{ Conformer } \\
\cline { 3 - 5 } K79H & His79 & $52\left(54^{c}\right)$ & $79\left(51^{c}\right)$ & 20 \\
T78C/K79G & Cys78 & 27 & 15 & 10 \\
\hline
\end{tabular}

${ }^{a}$ Calculated with POPS (Parameter OPtimized Surfaces) ${ }^{15}$ method. ${ }^{b}$ Structural models are displayed in Figure S1. ${ }^{c}$ With His79 protonated, see Figure S5A for the interactions of His79 with a nearby heme propionate. 

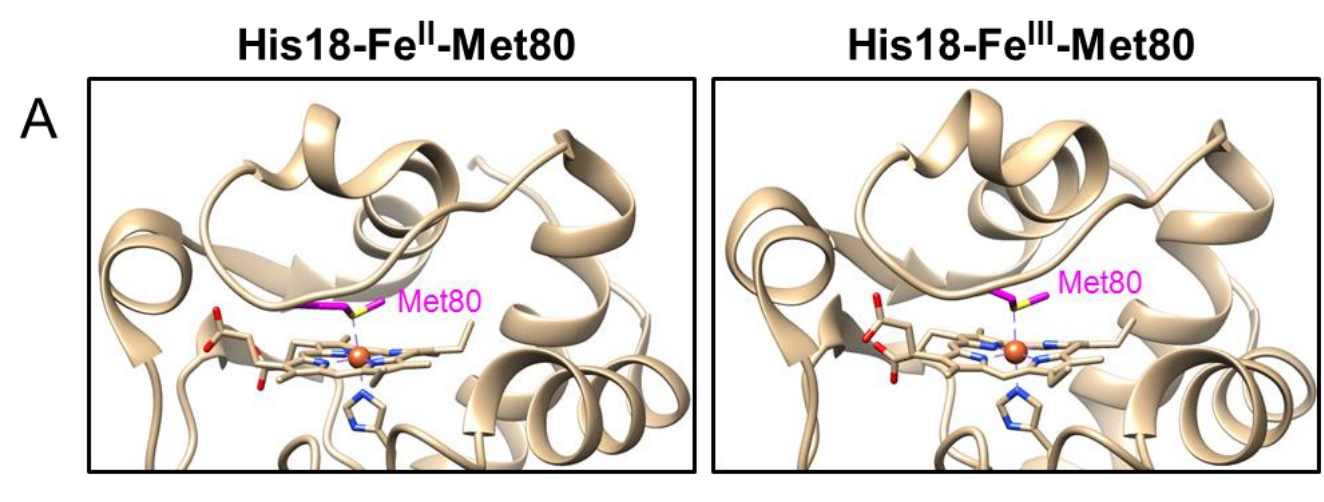

B
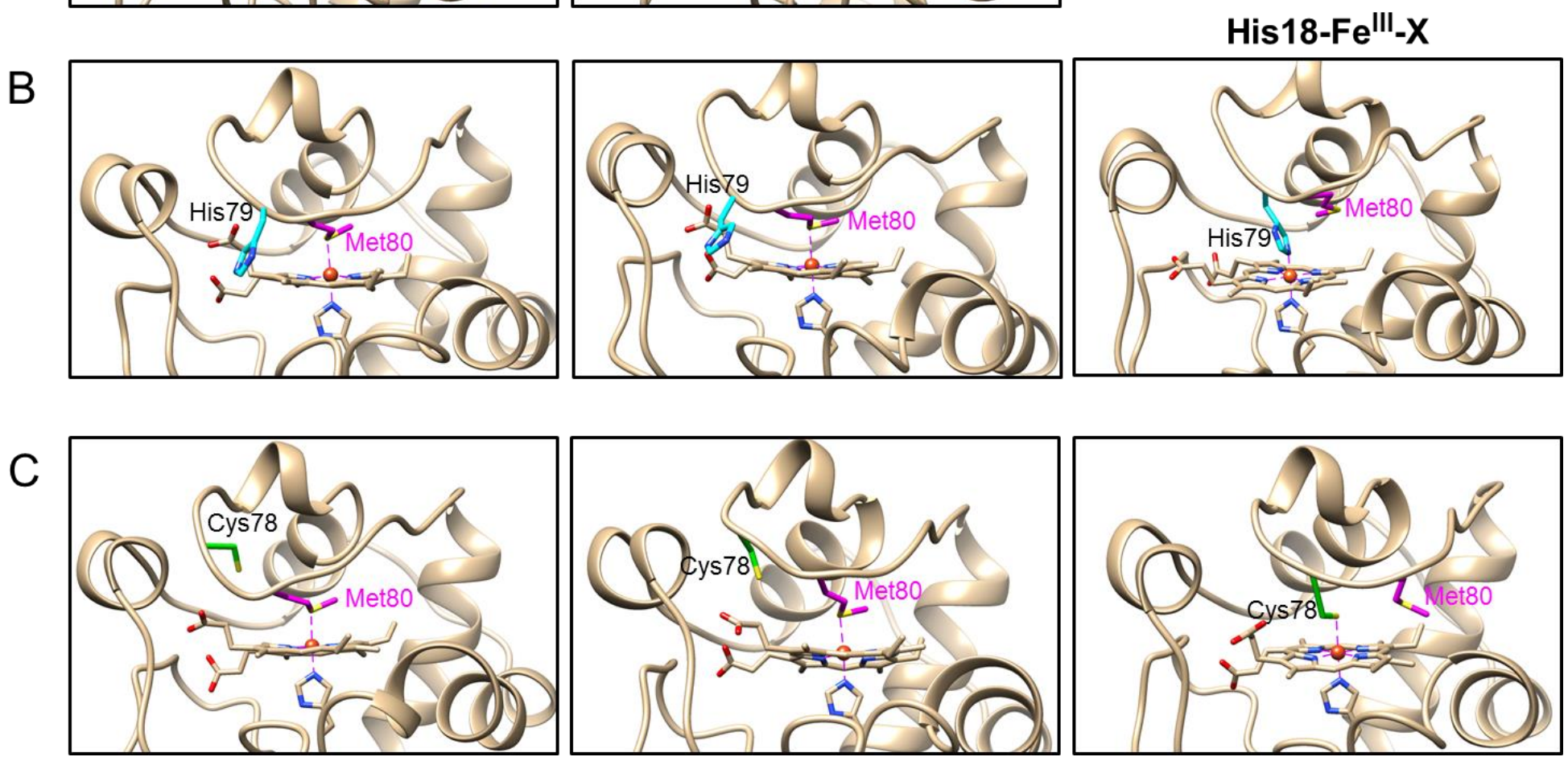

Figure S1. (A) Structures of ferrous (2YCC.pdb) ${ }^{13}$ and ferric (1YCC.pdb) ${ }^{14}$ yeast iso-1 cyt $c$. Structural models of (B) K79H and (C) T78C/K79G. In panels B and C, the ferrous conformer with Met80-ligation (left), the ferric conformers with Met80-ligation (middle) and His79 or Cys78-ligation (right) are shown. 

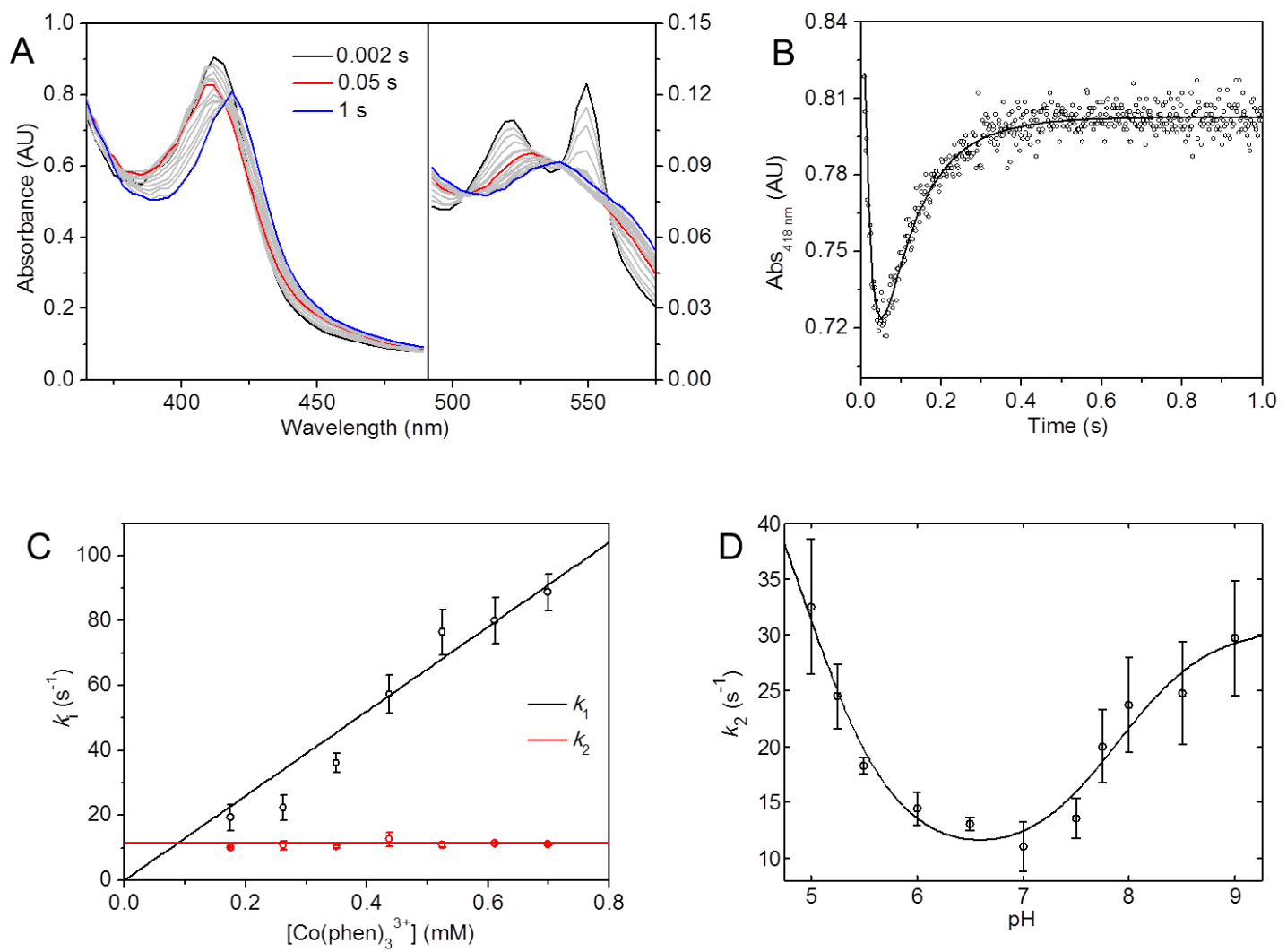

Figure S2. (A) Spectral changes in the Soret (left) and Q-band (right) regions for oxidation of ferrous T78C/K79G cyt $c$ by $\mathrm{Co}(\text { phen })_{3}{ }^{3+}$ in a $10 \mathrm{mM}$ sodium phosphate buffer at $\mathrm{pH} 7.0$ containing $100 \mathrm{mM} \mathrm{NaCl}$. Final concentrations of $\mathrm{Co}(\mathrm{phen}){ }_{3}{ }^{3+}$ and the protein in this experiment were $0.44 \mathrm{mM}$ and about $8 \mu \mathrm{M}$, respectively. (B) The time course of the absorbance at $418 \mathrm{~nm}$ under the same conditions as in panel A, showing spectral changes from both electron-transfer and the Met-to-Cys ligand-switch steps. The curve was fit to a triexponential function with $k_{3}$ equal to the value obtained from kinetics measurements of oxidation by $\mathrm{Fe}(\mathrm{CN})_{6}{ }^{3-}$ (Figure $\mathrm{S} 3 \mathrm{C}$ ). (C) The dependence of $k_{1}$ and $k_{2}$ values on concentration of $\mathrm{Co}(\mathrm{phen})_{3}{ }^{3+}$. (D) The $\mathrm{pH}$ dependence of $k_{2}$ values from oxidation studies of ferrous $778 \mathrm{C} / \mathrm{K} 79 \mathrm{G}$ cyt $c$ yielded two values of $\mathrm{p} K_{\mathrm{a}}^{\text {int,ox }}$ :

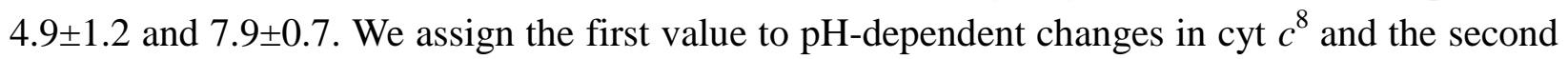
value to deprotonation of Cys78. 

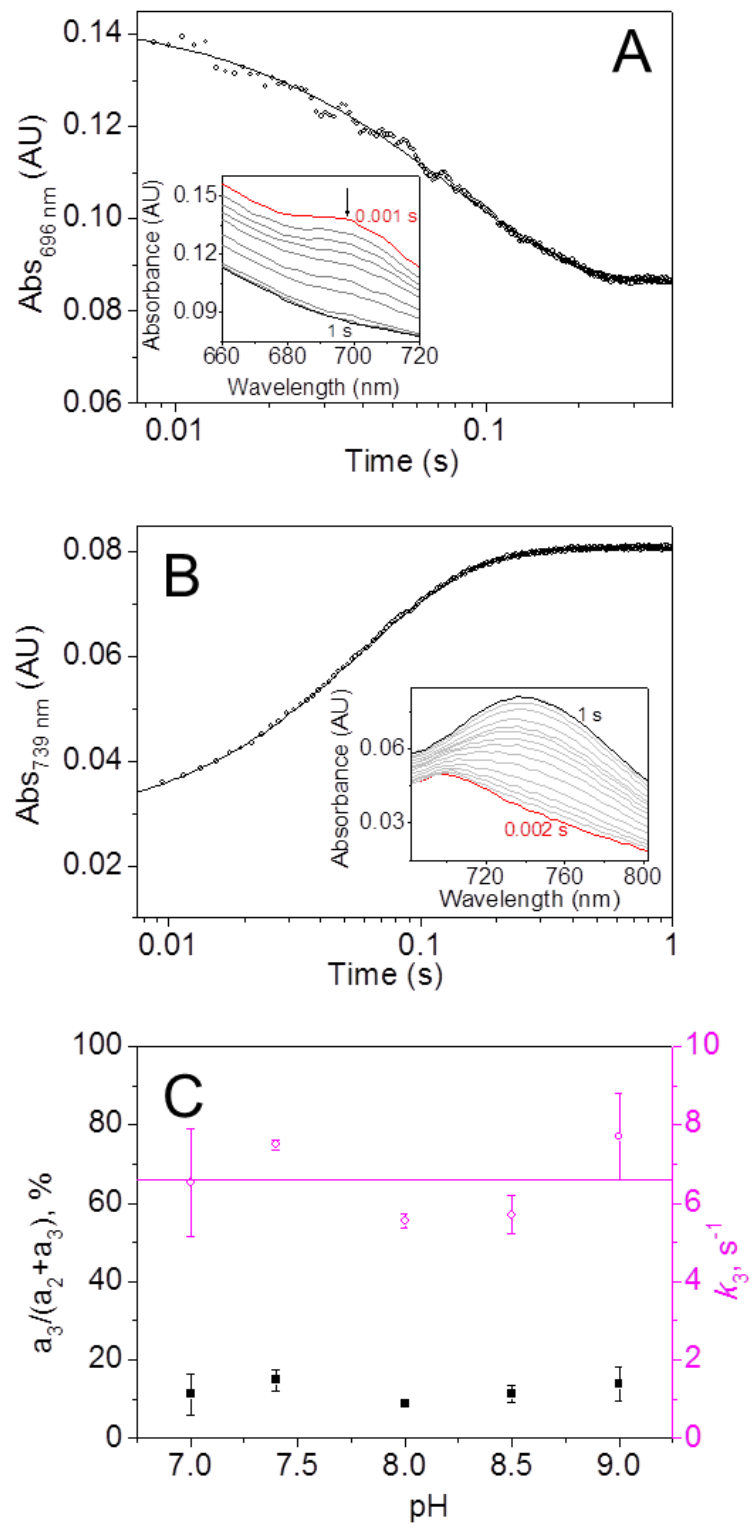

Figure S3. Time courses and spectral changes (insets) in the charge-transfer region for oxidation of ferrous (A) $\mathrm{K} 79 \mathrm{H}$ and (B) $\mathrm{T} 78 \mathrm{C} / \mathrm{K} 79 \mathrm{G}$ cyt $c$ by $\mathrm{Fe}(\mathrm{CN})_{6}{ }^{3-}$ in a $10 \mathrm{mM}$ sodium phosphate at $\mathrm{pH} 7.4$ containing $100 \mathrm{mM} \mathrm{NaCl}$. The final concentrations of ferrous $\mathrm{K} 79 \mathrm{H}$ and $\mathrm{T} 78 \mathrm{C} / \mathrm{K} 79 \mathrm{G}$ cyt $c$ were $70 \mu \mathrm{M}$ and $50 \mu \mathrm{M}$, respectively and the concentration of $\mathrm{Fe}(\mathrm{CN})_{6}{ }^{3-}$ was $1.5 \mathrm{mM}$. Under these conditions the ET step ( $k_{1}$ in Scheme 1) is too fast to be detected. For $\mathrm{K} 79 \mathrm{H}$ cyt $c$, monoexponential fit of the time dependence in panel A yielded $k_{2}=14.2 \pm 1.1 \mathrm{~s}^{-1}$. For T78C/K79G cyt $c$, biexponential fit of the time dependence in panel B yielded $k_{2}=18.6 \pm 0.3$ $\mathrm{s}^{-1}$ and $k_{3}=7.5 \pm 0.2 \mathrm{~s}^{-1}$. (C) $\mathrm{pH}$ independence of the rate constant $k_{3}$ and relative amplitude $a_{3}$ for the slowest phase in oxidation reaction of $\mathrm{T} 78 \mathrm{C} / \mathrm{K} 79 \mathrm{G}$ cyt $c$. We suggest that this phase corresponds to the Met80-to-Lys73 ligand switch at the ferric heme iron in the minor species having oxidized Cys78. 


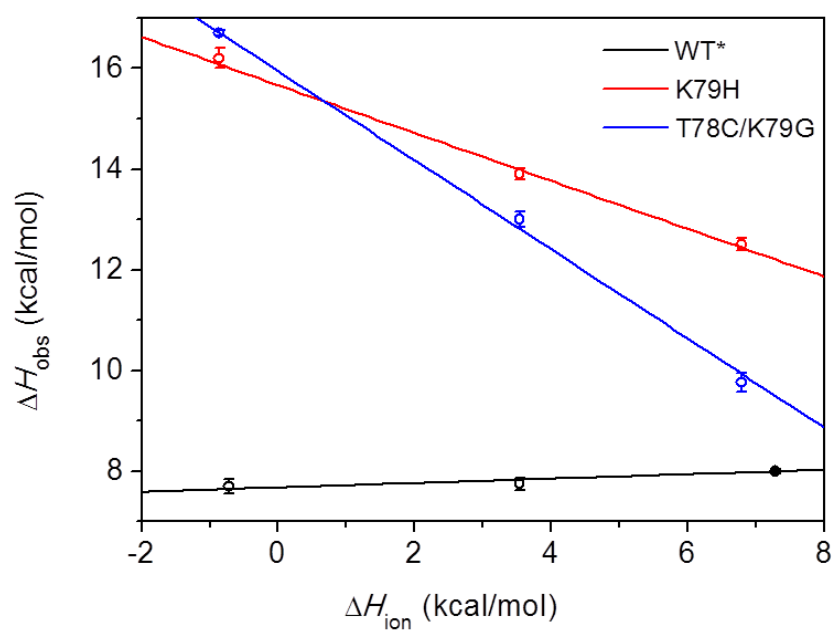

Figure S4. The observed enthalpy $\Delta H_{\mathrm{obs}}$ versus the ionization enthalpy of buffers $\Delta H_{\text {ion }}$ for oxidation of $\mathrm{WT}^{*}, \mathrm{~K} 79 \mathrm{H}$, and $\mathrm{T} 78 \mathrm{C} / \mathrm{K} 79 \mathrm{G}$ cyt $c$ variants by $\mathrm{Co}(\mathrm{phen})_{3}{ }^{3+}$ at $\mathrm{pH} 6.0$. The slopes $\Delta n_{\mathrm{H}+}$ and the intercepts $\Delta H_{0}$ of the linear fits of these dependences to eq 1 are listed in Table 2. 

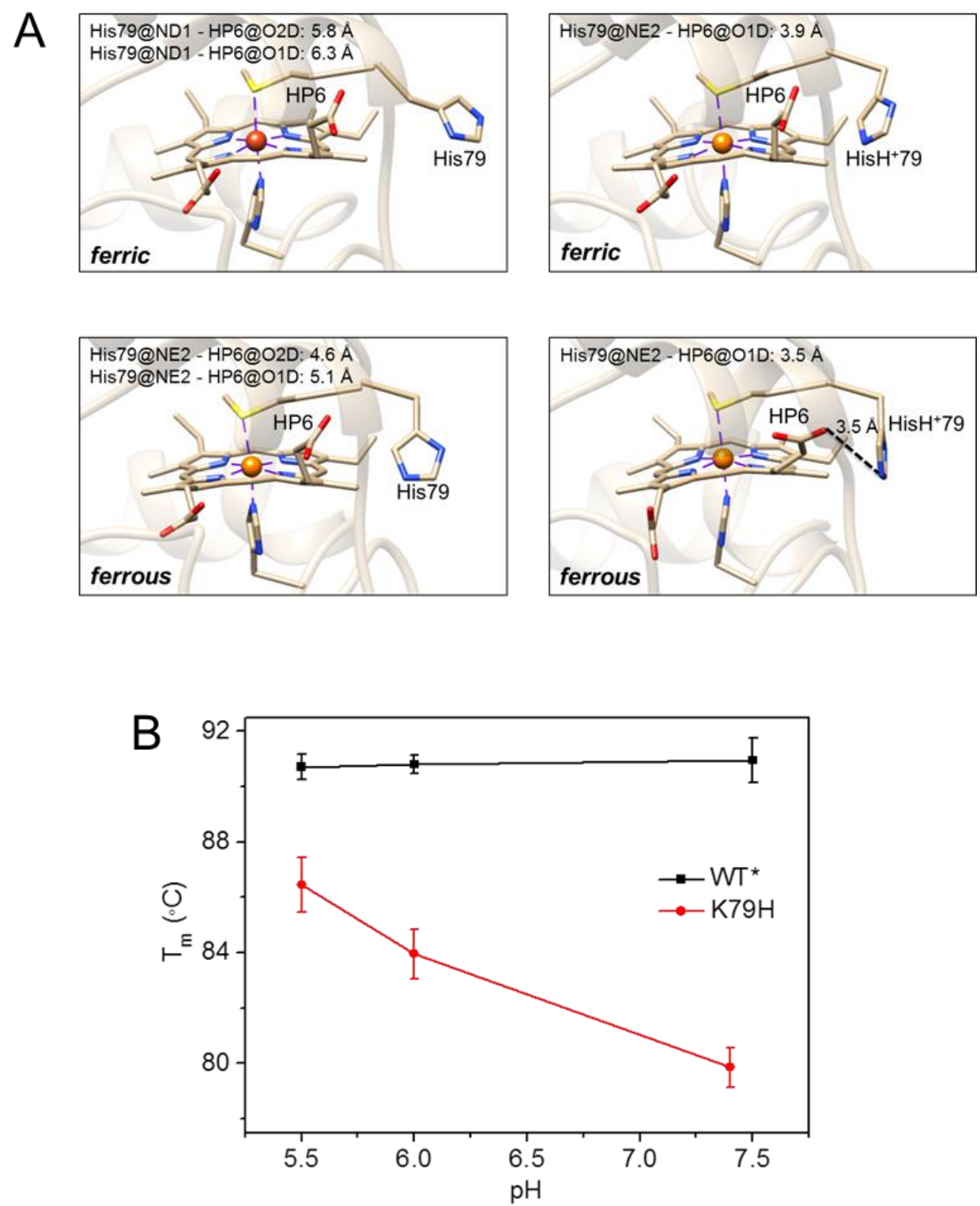

Figure S5. (A) Interactions between His79 and heme propionate HP6 in ferric and ferrous Met80-ligated conformers of $\mathrm{K} 79 \mathrm{H}$. The close proximity of the two groups in the ferrous conformer with the protonated His79 $\left(\mathrm{HisH}^{+} 79\right)$ provides a rationale for stabilization of this conformer. In comparison, the more distant location and the +3 charge of the ferric iron $(+1$ for the porphyrin core) near His79H+ will not be as favorable. (B) $\mathrm{pH}$ dependence of midpoint temperatures $\left(T_{\mathrm{m}}\right)$ from the thermal denaturation experiments with ferrous $\mathrm{WT}^{*}$ and $\mathrm{K} 79 \mathrm{H}$ cyt $c$. Unfolding transitions were monitored by following ellipticity at $222 \mathrm{~nm}$ with CD spectroscopy. Both ferrous $\mathrm{WT}^{*}$ and $\mathrm{K} 79 \mathrm{H}$ are Met80-ligated but His79 undergoes deprotonation in the studied $\mathrm{pH}$ range $\left(\mathrm{p} K_{\mathrm{a}}{ }^{\text {red }}=7.19 \pm 0.08\right)$. While the stability of ferrous $\mathrm{WT}^{*}$ cyt $c$ does not appear to change much in the $\mathrm{pH}$ range from 5.5 to 7.4 , the stability of ferrous $\mathrm{K} 79 \mathrm{H}$ cyt $c$ decreases at higher $\mathrm{pH}$ when His79 gets deprotonated suggesting that the ferrous conformer with protonated His79 is more stable than the one with deprotonated His79. 

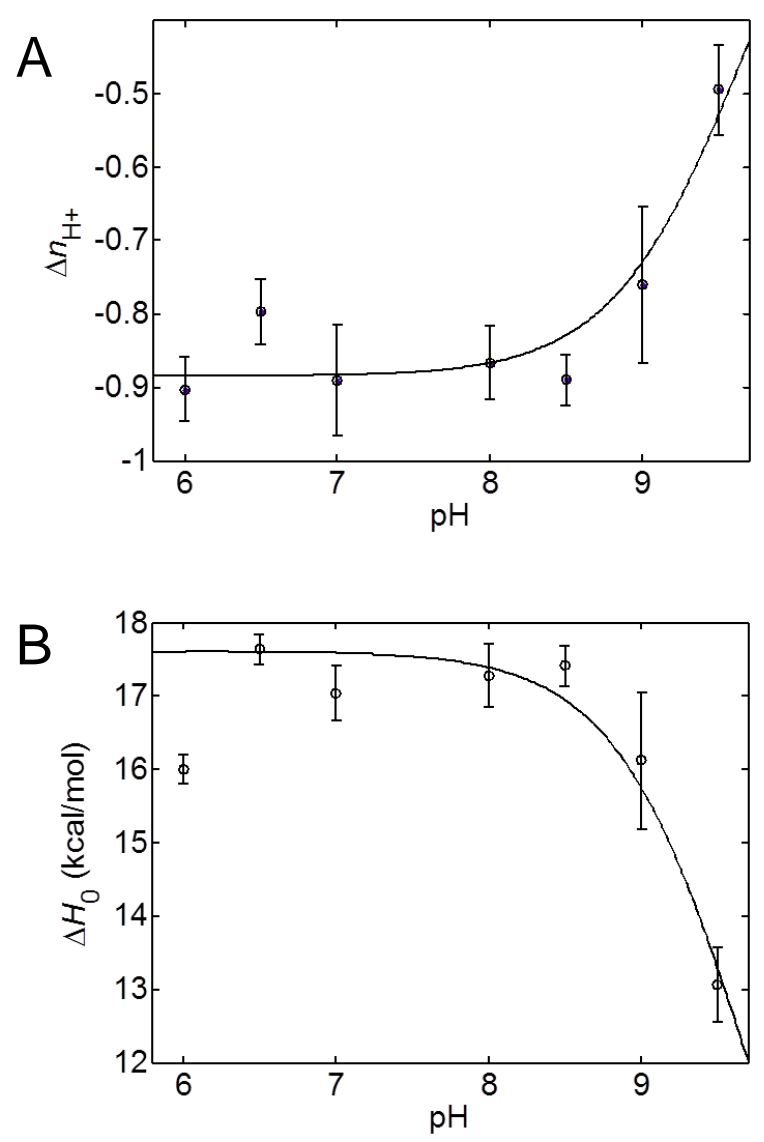

Figure S6. (A) $\mathrm{pH}$ dependence of net proton change $\Delta n_{\mathrm{H}+}$ for oxidation of ferrous $\mathrm{T} 78 \mathrm{C} / \mathrm{K} 79 \mathrm{G}$ cyt $c$ by $\mathrm{Co}(\text { phen })_{3}{ }^{3+}$. Fit (solid line) of this dependence to a modified eq 5 with $\mathrm{p} K_{\mathrm{a}}{ }^{\text {ox }}=2.5$ yielded $\mathrm{p} K_{\mathrm{a}}^{\text {red }}=9.7 \pm 0.3$. A scaler $\alpha=0.88 \pm 0.07$ to multiply the dependence in eq 5 was included to account for partial oxidation $(<10 \%)$ of Cys78 in $\mathrm{T} 78 \mathrm{C} / \mathrm{K} 79 \mathrm{G}$ samples. We have previously shown that Cys78 in this cyt $c$ variant gets readily oxidized. ${ }^{2}$ (B) $\mathrm{pH}$ dependence of the enthalpy change in a buffer with zero ionization enthalpy $\Delta H_{0}$ and its fit (solid line) to eq 6 with $\mathrm{p} K_{\mathrm{a}}{ }^{\mathrm{ox}}=2.5$ and the $\mathrm{p} K_{\mathrm{a}}^{\text {red }}$ value determined from the fit in the panel A. This analysis yielded parameters in Table 1. 

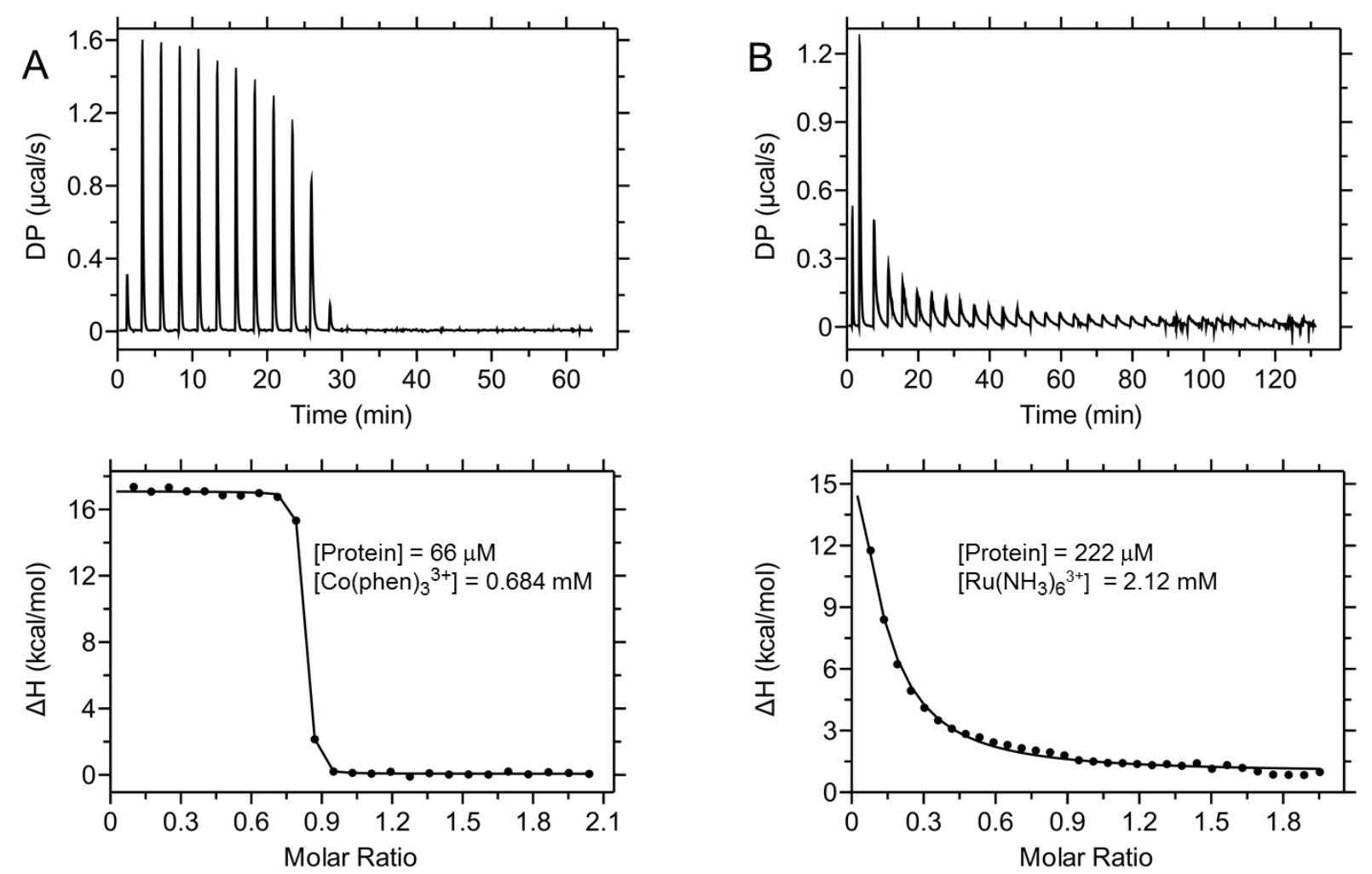

Figure S7. ITC thermograms and the corresponding titration curves for oxidation of T78C/K79G cyt $c$ by $\mathrm{Co}$ (phen $)_{3}{ }^{3+}$ and $\mathrm{Ru}\left(\mathrm{NH}_{3}\right)_{6}{ }^{3+}$ in a $10 \mathrm{mM}$ maleate buffer at $\mathrm{pH} 6.0$ containing $100 \mathrm{mM}$ $\mathrm{NaCl}$. While the $\mathrm{Co}$ (phen) $3^{3+}$ experiments allowed for accurate determination of reaction enthalpies $\Delta H_{\mathrm{obs}}$, the titration curve lacked the definition in the transition region and was not suitable for determination of the $K_{\text {eq }}$ value. Analysis of the data in panel B has yielded $K_{\text {eq }}=0.19 \pm 0.03$ for oxidation of $\mathrm{T} 78 \mathrm{C} / \mathrm{K} 79 \mathrm{G}$ cyt $c$ by $\mathrm{Ru}\left(\mathrm{NH}_{3}\right)_{6}{ }^{3+}$ and $E=93 \pm 3 \mathrm{mV}$ for the apparent reduction potential $\left(\mathrm{Cys} 78-\mathrm{Fe}^{3+}-\mathrm{His} 18+e^{-} \rightarrow \mathrm{Met} 80-\mathrm{Fe}^{2+}-\mathrm{His} 18\right.$ ) of the heme iron in this protein. 


\section{SI References}

(1) Duncan, M. G.; Williams, M. D.; Bowler, B. E. Compressing the free energy range of substructure stabilities in iso-1-cytochrome c. Prot. Sci. 2009, 18, 1155-1164.

(2) Amacher, J. F.; Zhong, F.; Lisi, G. P.; Zhu, M. Q.; Alden, S. L.; Hoke, K. R.; Madden, D. R.; Pletneva, E. V. A compact structure of cytochrome $c$ trapped in a lysine-ligated state: loop refolding and functional implications of a conformational switch. J. Am. Chem. Soc. 2015, 137, 8435-8449. .

(3) Pound, G. J.; Pletnev, A. A.; Fang, X.; Pletneva, E. V. A small fluorophore reporter of protein conformation and redox state Chem. Commun. 2011, 47, 5714-5716.

(4) Maki, N. Methods of Preparing the 2,2' -Dipyridyl and 1,10-Phenanthroline Cobalt(III) Complexes of the [CoX2dip2]- and [CoX2phen2]-Type. Bull. Chem. Soc. Jpn. 1969, 42, 2275-2281.

(5) Welch, T. W.; Thorp, H. H. Distribution of metal complexes bound to DNA determined by normal pulse voltammetry. J. Phys. Chem. 1996, 100, 13829-13836.

(6) Wright, C.; Sykes, A. G. Interconversion of CuI and CuII forms of galactose oxidase: comparison of reduction potentials J. Inorg. Biochem. 2001, 85, 237-243.

(7) Appleby, C. A.; Morton, R. K. Lactic dehydrogenase and cytochrome $b_{2}$ of baker's yeast; purification and crystallization. Biochem. J. 1959, 71, 492-499.

(8) Zhong, F.; Lisi, G. P.; Collins, D. P.; Dawson, J. H.; Pletneva, E. V. Redox-dependent stability, protonation, and reactivity of cysteine-bound heme proteins. Proc. Natl. Acad. of Sci. USA 2014, 111, E306-E315.

(9) Wiseman, T.; Williston, S.; Brandts, J. F.; Lin, L.-N. Rapid measurement of binding constants and heats of binding using a new titration calorimeter. Anal. Biochem. 1989, 179, 131-137.

(10)Sørlie, M.; Chan, J. M.; Wang, H.; Seefeldt, L. C.; Parker, V. D. Elucidating thermodynamic parameters for electron transfer proteins using isothermal titration calorimetry: application to the nitrogenase Fe protein. J. Biol. Inorg. Chem. 2003, 8, 560-566.

(11) Taniguchi, V. T.; Ellis, W. R.; Cammarata, V.; Webb, J.; Anson, F. C.; Gray, H. B. In Electrochemical and Spectrochemical Studies of Biological Redox Components; AMERICAN CHEMICAL SOCIETY: 1982; Vol. 201, p 51-68. 
(12)Lim, H. S.; Barclay, D. J.; Anson, F. C. Formal potentials and cyclic voltammetry of some ruthenium-ammine complexes. Inorg. Chem. 1972, 11, 1460-1466.

(13)Berghuis, A. M.; Brayer, G. D. Oxidation state-dependent conformational changes in cytochrome c. J. Mol. Biol. 1992, 223, 959-976.

(14)Louie, G. V.; Brayer, G. D. High resolution refinement of yeast iso-1-cytochrome $c$ and comparisons with other eucaryotic cytochromes c. J. Mol. Biol. 1990, 214, 527-555.

(15)Cavallo, L.; Kleinjung, J.; Fraternali, F. POPS: A fast algorithm for solvent accessible surface areas at atomic and residue level. Nucleic Acids Res. 2003, 31, 3364-3366.

(16)Deng, Y.; Zhong, F.; Alden, S. L.; Hoke, K. R.; Pletneva, E. V. The K79G mutation reshapes the heme crevice and alters redox properties of cytochrome c. Biochemistry 2018, 57, 5827-5840.

(17)Goldberg, R. N.; Kishore, N.; Lennen, R. M. Thermodynamic quantities for the ionization reactions of buffers. J. Phys. Chem. Ref. Data 2002, 31, 231-370.

(18)Xie, D.; Gulnik, S.; Collins, L.; Gustchina, E.; Suvorov, L.; Erickson, J. W. Dissection of the $\mathrm{pH}$ dependence of inhibitor binding energetics for an aspartic protease: direct measurement of the protonation states of the catalytic aspartic acid residues. Biochemistry 1997, $36,16166-16172$.

(19)Fabbrizzi, L.; Micheloni, M.; Paoletti, P.; Schwarzenbach, G. Protonation processes of unusual exothermicity. J. Am. Chem. Soc. 1977, 99, 5574-5575.

(20)Feinberg, B. A.; Liu, X.; Ryan, M. D.; Schejter, A.; Zhang, C.; Margoliash, E. Direct Voltammetric Observation of Redox Driven Changes in Axial Coordination and Intramolecular Rearrangement of the Phenylalanine-82-Histidine Variant of Yeast Iso-1-cytochrome c. Biochemistry 1998, 37, 13091-13101. 